\title{
The effect of Alexander technique training program: A qualitative study of ordinary behavior application
}

\author{
Soo-Yeon Kim', Soon Gi Baek,** \\ ${ }^{1}$ Kohwang Medical Research Institute, College of Medicine, Kyung Hee University, Seoul, Korea \\ ${ }^{2}$ Department of Sports Health Medicine, College of Health Science, Jungwon University, Goesan-gun, Chungcheongbuk-do, Korea
}

The purpose of this study was to configure and apply the Alexander technique training program and assess the effect of program through physical, emotional and behavioral aspects. To achieve the research aims, qualitative research method had been conducted, subjecting 8 people, who were participating in Alexander Technique training program for this study. The study used focus group interview method for collecting date and employed for the interview method by mixing the semi-structured and unstructured questionnaire. The results were followings. First, one could develop body awareness and body consciousness through experiencing lived bodily sensation. Second, from Alexan- der Technique training program, people experienced psycho \& physical's equilibrium. Third, one could change not only the manner of use of body but also the attitude to the life from conscious attention to daily ordinary movement. The results provided empirical evidence of Alexander Technique training program's functions in terms of physical, emotional and behavioral aspect through the process of consciousness control from lived body education.

Keywords: Alexander technique, Mind-body therapy, Somatic education, Qualitative study

\section{INTRODUCTION}

Alexander technique is one of the Mind-Body therapy methods, originally developed more than $120 \mathrm{yr}$, helps individuals to change self-damaging postural and movement habits and to modify habitual responses to stimuli, which can include pain and stress. Alexander Technique is not about maintaining a certain posture or "doing" certain behavior. It is about to apply cognition to fulfill the achievement of action (Woodman and Moore, 2012). Therefore Alexander technique is understood as not a therapy or fixed forms of exercise but re-education program of sensory and motor system.

Alexander technique's teaching methods are based on guiding individuals in everyday tasks like standing and sitting to help them experience changed habitual movement behavior in a way that demands less effort. The instruction program used in Alexander technique education differs markedly from that in disciplines such as physiotherapy or osteopathy. Although the physiological and neurological basis of the Alexander technique is unclear yet, it is known to give positive effect of motor behaviors. Alexander technique training has been shown to guide to changed postural control in standing by reducing axial stiffness and increasing the adaptability of muscle tone (Cacciatore et al., 2011a). Alexander technique training has also been demonstrated to lead to changes in the coordination of voluntary movement, prolonged and smoother weight transfer, reduced body acceleration and recovered automatic balance (Cacciatore et al., 2005; 2011b)

Also, Alexander technique has been applied to medical conditions involving such as chronic back pain, arthritis, and Parkinson's disease (Dennis and Cates, 2012; Stallibrass and Hampson, 2001). Cacciatore et al. (2011) suggested that dynamic modulation of postural tone could be enhanced through Alexander technique training. Especially, this study showed low back pain people decreased trunk and hip stiffness following Alexander technique training. Furthermore, Alexander technique education has been applied in the fields of performing arts such as theatre, dance and
${ }^{*}$ Corresponding author: Soon Gi Baek

Department of Leisure Sports, College of Health Science, Jungwon University,

85 Munmu-ro, Goesan-gun, Chungcheongbuk-do 367-700, Korea

Tel: +82-43-830-8840, Fax: +82-43-830-8679, E-mail: bsg@jwu.ac.kr

Received: November 30, 2014 / Accepted: December 17, 2014
This is an Open Access article distributed under the terms of the Creative Commons Attribution Non-Commercial License (http://creativecommons.org/licenses/by-nc/3.0/) which permits unrestricted non-commercial use, distribution, and reproduction in any medium, provided the original work is properly cited. 
music, with assessed improvements in performance (Fortin and Girard, 2005).

Many studies about Alexander technique have examined the efficacy of posture movement related to skill improvements (eg. sports skill and music skill) or pain relief. Considering Alexander technique is one of the Mind-Body therapy, which could utilize methods designed to facilitate the mind's capacity to involve bodily function and symptoms, it is necessary to identify the effect of improving not only physical aspect but also emotional and behavioral aspects. Therefore, the purpose of this study was to configure and apply the Alexander technique training program and assess the efficacy of Alexander program in terms of physical, emotional and behavioral aspects.

\section{MATERIALS AND METHODS}

\section{Participants}

Participants for the current study were selected 8 people who were taking Alexander technique group training program at Korean Alexander Technique Association. The researcher explained to participants the research purpose in advance, obtained prior consents from the participants about using the recorder and video camera to secure the research ethics of the qualitative research method, and conducted the study after collecting the consent forms from participants. Table 1 shows the general characteristics of participants in this study.

\section{Procedure}

The present study employed focus group study methods to col-

Table 1. General characteristics of research participants

\begin{tabular}{|c|c|c|c|c|}
\hline No & Gender & Age & $\begin{array}{c}\text { Academic } \\
\text { background }\end{array}$ & Occupation \\
\hline 1 & M & 42 & $\begin{array}{c}\text { Under } \\
\text { Graduate school }\end{array}$ & Photographer \\
\hline 2 & $M$ & 41 & $\begin{array}{c}\text { Under } \\
\text { Graduate school }\end{array}$ & NGO organization office worker \\
\hline 3 & $\mathrm{M}$ & 45 & $\begin{array}{c}\text { Under } \\
\text { Graduate school }\end{array}$ & Physical therapist \\
\hline 4 & $\mathrm{M}$ & 26 & $\begin{array}{c}\text { Under } \\
\text { Graduate school }\end{array}$ & Computer programmer \\
\hline 5 & M & 42 & $\begin{array}{c}\text { Under } \\
\text { Graduate school }\end{array}$ & Won Buddhism office worker \\
\hline 6 & $\mathrm{~F}$ & 30 & Graduate school & Rehabilitation therapist \\
\hline 7 & $\mathrm{~F}$ & 38 & $\begin{array}{c}\text { Under } \\
\text { Graduate schoo }\end{array}$ & Advertising \\
\hline 8 & $\mathrm{~F}$ & 45 & Graduate school & Yoga teacher \\
\hline
\end{tabular}

lect data because focus group is one of the qualitative research methods which allow researchers to gain rich information from key informants (Stewart et al., 2007).

\section{Program description by session}

The program consisted of Alexander technique's basic theory and daily movement application for understanding behavioral habit and changing its responses to stimuli. Each of the four, twohour sessions included explanation of the basic concepts of Alexander technique: awareness, direction, inhibition, Primary control, and daily movement activity: grounding, sitting, bending, ordinary movement. Basic concepts of Alexander technique was as follow (Table 2)

After the program focus group interview was provided by interviewer. Common topics for the focus group interview included: (a) opinion about today's Alexander technique program, (b) physical experiences from Alexander technique program, (c) emotional experiences from Alexander technique program, (d) behavioral experiences from Alexander technique program

\section{Session one: kinesthetic awareness and grounding}

During session one, participants experienced kinesthetic body awareness training by grounding activity. Alexander discovered sensory feedback, called kinesthetic sense, to be aware of own physical condition. Kinesthetic sense provided the information to the brain about physical tension. Alexander technique training helped them to gain kinaesthesia: sensory awareness and conscious control of the whole movement.

\section{Session two: Direction and sitting}

During session two, participants discovered the concept of "di-

Table 2. Basic concept of Alexander technique

\begin{tabular}{ll}
\hline Concept & \multicolumn{1}{c}{ Meaning } \\
\hline Awareness & $\begin{array}{l}\text { The first step in the practice of conscious control } \\
\text { An individual is aware of what one is doing or thinking }\end{array}$ \\
Primary control & $\begin{array}{c}\text { The delicate musculoskeletal relationship between the } \\
\text { head, neck, and torso }\end{array}$ \\
Inhibition & $\begin{array}{c}\text { After becoming aware of what one is doing, and thinking, } \\
\text { the individual stops doing or thinking in the same pattern } \\
\text { (old habit) }\end{array}$ \\
Pirection & $\begin{array}{l}\text { Practice of conscious control } \\
\text { individual directs a new form of performance to take action }\end{array}$ \\
Conscious & $\begin{array}{l}\text { The control of self use } \\
\text { Either in psychological reaction/emotion or physical } \\
\text { movement, or both-through conscious thinking }\end{array}$
\end{tabular}


rection" and embodied it through sting activity. Alexander technique's direction was as following: "to let the neck be free, to allow the head go forward and up, so that the back can lengthen and widen," These direction represented the most frequently quoted and used portion of the Alexander technique's wisdom. Direction played two roles as not only mental instructions but also specific body part's directivity. It was a process where the brain projected the message to the physical mechanism to conduct the activity of the mechanism into performance.

\section{Session three: Inhibition and bending}

During session three, participants understood the concept of "inhibition" in terms of Alexander technique approach. Alexander pointed out that many people prepared for action by creating unnecessary muscle tension by end-gaining. The end-gaining was a reflex action which tended to by-pass the reasoning brain. Modern society people showed unconsciously reacting on an input-output system so that activation is directed toward satisfying the input as soon as possible. Therefore, "throughput" was necessary to adequate preparation for the succeeding activity. From this viewpoint, throughput was understood as inhibition.

\section{Session four: Primary control and breathe}

During Session four, participants explored the concept of "primary control" and embodied primary control by breathing activity. Alexander found out his unconscious mis-use of the neck and head and built up the concept of "primary control" from precise observation. Primary control meant that the delicate musculoskeletal relationship between the head, neck, and torso. During the session, participants understood the relationship between the head, neck, and torso.

\section{Analysis}

The time for focus group was between $69 \mathrm{~min}$ and the focus groups were recorded through both audio and video devices. The recorded files were transcribed in verbatim, and the total words were 40.246 in Korean. For analyzing data, Patton's (2002) thematic content analysis was used. First step was reading and re-reading the original transcriptions to understand interviewee's story. The second step was breaking down the raw data into meaning unit so that it could possible to develop the initial classification system by identifying, defining, labeling, and classifying the data. The third step was developing systematic classification by uniting the lower order themes. From this process, "essence phrase" is maintaining. The fourth step was developing a process-outcome matrix across the three higher order themes and interpreting and categorizing raw data into themes.

\section{RESULTS}

The analysis procedure resulted in two higher order themes related to the effect of Alexander technique training program in terms of contents' change. Contents of Changes themes were divided into three lower order themes, namely physical change, emotional change, behavioral change (Table 3). For examining the effect of Alexander technique training program more specifically, we analyzed participants' experiences by contents of class.

\section{Session one: Kinaesthesia and grounding}

In session one, participants understood kinaesthesia concept via "grounding" activity. From grounding activity of standing movement, participants built up body awareness by themselves. It could be supportive to notice one's body reaction by emotional

Table 3. Coding framework

\begin{tabular}{|c|c|c|c|}
\hline & First order theme & Second order theme & Raw data theme \\
\hline \multirow{5}{*}{$\begin{array}{l}\text { Global change } \\
\text { through out } \\
\text { the activity }\end{array}$} & $\begin{array}{l}\text { Physical } \\
\text { change }\end{array}$ & $\begin{array}{l}\text { Body awareness } \\
\text { Body consciousness }\end{array}$ & $\begin{array}{l}\text { eg. Female B: As I have recognized the sit bone's exact location \& sit on the sit bone, I could sit longer than before. } \\
\text { eg. Male E: When I do a 'direction', I notice the pain form left ankle and waist. }\end{array}$ \\
\hline & $\begin{array}{l}\text { Emotional } \\
\text { change }\end{array}$ & $\begin{array}{l}\text { Stability and slowness } \\
\text { of mind }\end{array}$ & $\begin{array}{l}\text { eg. Male B: As teacher explained the concept of "grounding", she mentioned we all have connected to center of } \\
\text { the earth by gravity. It was impressive to me. As I got more connectivity to environment, I felt more emotionally } \\
\text { stable } \\
\text { eg. Male A: Before attending this workshop, even though no one was to pull me, I felt by dragged. Nowadays, as } \\
\text { I've noticed speed of life is slow down. I have enjoyed the time to attend the office }\end{array}$ \\
\hline & & $\begin{array}{l}\text { Escape from negative } \\
\text { emotion }\end{array}$ & $\begin{array}{l}\text { eg. Male D: I think the pain is related to negative emotion. I have enjoyed studying. However, as I noticed the pain, } \\
\text { I recognized study is painful thing. Recently, as I feel less pain from my body, I enjoy studying }\end{array}$ \\
\hline & $\begin{array}{r}\text { Behaviora } \\
\text { changel }\end{array}$ & Concentration & $\begin{array}{l}\text { eg. Male A: As I applied the concept Alexander Technique to my daily life, I could freely control my concentration } \\
\text { energy; I could not only continually focus on the joy but also halt it. It increases the job effectiveness. }\end{array}$ \\
\hline & & $\begin{array}{l}\text { Awareness of daily } \\
\text { life pattern }\end{array}$ & eg. Male B: After this workshop, I recognize I prefer to use left-side space. \\
\hline
\end{tabular}


change. Also, grounding activity played a role in identifying body movement not by thinking process but by sensing process using proprioception. For example, one participant said:

$<$ Male B >

"As teacher explained the concept of "grounding", she mentioned we all have connected to center of the earth by gravity. It was impressive to me. As I got more connectivity to environment, I felt more emotionally stable."

\section{Session two: Direction and sitting}

In session two, participants understood what direction is and how direction worked to body. Direction played two roles as not only mental instructions but also specific body part's directivity. It was a process where the brain projected the message to the physical mechanism to conduct the activity of the mechanism into performance. During the session, participants understood body awareness by noticing exact body part location and directivity.

Participants said about body awareness and consciousness;

$<$ Female $\mathrm{B}>$

"As I have recognized the sit bone's exact location and sit on the sit bone, I could sit longer than before."

Also, another participant mentioned;

$<$ Male E >

"When I think Alexander technique's directions step by step, I notice the pain form left ankle and wais."

\section{Session three: Inhibition and bending}

In session three, we focused on Alexander technique's inhibition concept by bending activity. Participants explored habitual behavior what they are giving themselves. Then they discovered to inhibit those behaviors and instead give the new response by Alexander technique's direction. For example, one participant said about mind's slowness as follow:

$<$ Male A $>$

"Even though no one was to pull me, I had felt by dragged. However, after attending this program, as I've noticed speed of life is getting slow down, I have enjoyed the time to attend the office."

\section{Session four: Primary control and application to daily behavior}

In session four, we focused on Alexander technique's "primary control" concept and application to daily movement. From "body movement awareness from daily official behavior using primary control concept" activity, participants had a chance to explore the process of each experience by following the "means-whrerby" principle. They experienced more concentrated moment by consciousness control. For example, one participant said:

$<$ Female $\mathrm{C}>$

As I applied the concept Alexander technique to my daily life, I could freely control my concentration energy; I could not only continually focus on the joy but also halt it. It increases the job effectiveness."

\section{DISCUSSION}

The purpose of this study was to configure and apply the Alexander technique training program and assess the effect of program through physical, emotional and behavioral aspects. A qualitative research method had been conducted, subjecting 8 people, who were participating in Alexander technique training program to achieve this study.

Firstly, participants had developed body awareness and body consciousness through lived body experience. Result showed similarities with Galvao and Kemp (2005)'s study. He declared that musicians experienced through their own bodily practice under the guidance of an Alexander technique teacher. Result represented that uncontrollable habits could modified by 'conscious control' with lived bodily experience. Also Alexander technique helped participant to gain kinaesthesia: sensory awareness and conscious control of the whole movement.

Secondly, current study supported Alexander technique was the educational training program that provided people with support to integrate the functions of mind and body. In modern society, body and mind had been divided into two categories. The more human and civilized mankind becomes, the less there was some behavior which was purely physical and some other which is purely mental. Physical and metal separation resulted out psychophysical imbalance. In this study, people experienced psycho and physical's equilibrium from Alexander technique education.

Thirdly, this study showed how people transformed Alexander technique concept into the one's lifespan. According to Barlow (1991) when students of Alexander technique built up a conscious attention, they changed from passive recipient to active participant of the life. Similarly, current study subjects realized how they used their body within the daily ordinary behavior. From conscious attention to daily normal movement, they changed not only the manner of use of body but also the attitude to the life. From the Alexander technique training program, one could maintain third-person perspective through body awareness and body 
consciousness, to develop physically as well as emotional.

\section{CONFLICT OF INTEREST}

No potential conflict of interest relevant to this article was reported.

\section{REFERENCES}

Barlow W. The alexander technique: How to use your body without stress. New York, Warner Books, 1991.

Cacciatore TW, Gurfinkel VS, Horak FB, Day BL. Prolonged weight-shift and altered spinal coordination during sit-to-stand in practitioners of the Alexander Technique. Gait Posture 2011a;34:496-501.

Cacciatore TW, Gurfinkel VS, Horak FB, Cordo PJ, Ames KE. Increased dynamic regulation of postural tone through Alexander Technique training. Hum Mov Sci 2011b:30:74-89.

Cacciatore TW, Horak, FB, Henry SM. Improvement in automatic postur- al coordination following Alexander Technique lessons in a person with low back pain. Phys Ther 2005;85:565-578.

Dennis J. Cates C. Alexander technique for chronic asthma. Cochrane Database Syst Rev 2012;9:CD000995.

Fortin S, Girard F. Dancers' application of the Alexander technique. J Dance Educ 2005;5:125-131.

Galvao A, Kemp A. Kinaesthesia and instrumental music instruction: some implications. Psychol Music 2005;27:129-137.

Patton MQ.Two decades of developments in qualitative inquiry a personal, experimental perspective. Qual Soc Work 2002;1:261-283.

Stallibrass C, Hampson M. The Alexander technique: its application in midwifery and the results of preliminary research into Parkinson's. Complementary Ther Nurs Midwifery 2001;7:13-18.

Stewart DW, Shamdasani PN, Rook DW. Focus Group: Theory and Practice. London: Sage Publication, Inc., 2007.

Woodman JP, Moore NP. Evidence for the effectiveness of Alexander Technique lessons in medical and health-related conditions: a systematic review. Int J Clinical Practice 2012;66:98-112. 